\title{
Supplement material-
}

\section{Long Range Substrate Effects on the Stability and Reactivity of}

\section{Thiolated Self-Assembled Monolayers}

Tali Aqua, Hagai Cohen, Ayelet Vilan, Ron Naaman

The $\mathrm{O}$ 1s band increases under exposure to air both for DT and MT on GaAs (Figure $1 \mathrm{~A}, \mathrm{~B}$ ). However, in the case of the MT the increase rate is significantly higher (Figure $1 \mathrm{C}$ ). In addition, the peak slightly shifts to higher binding energy.

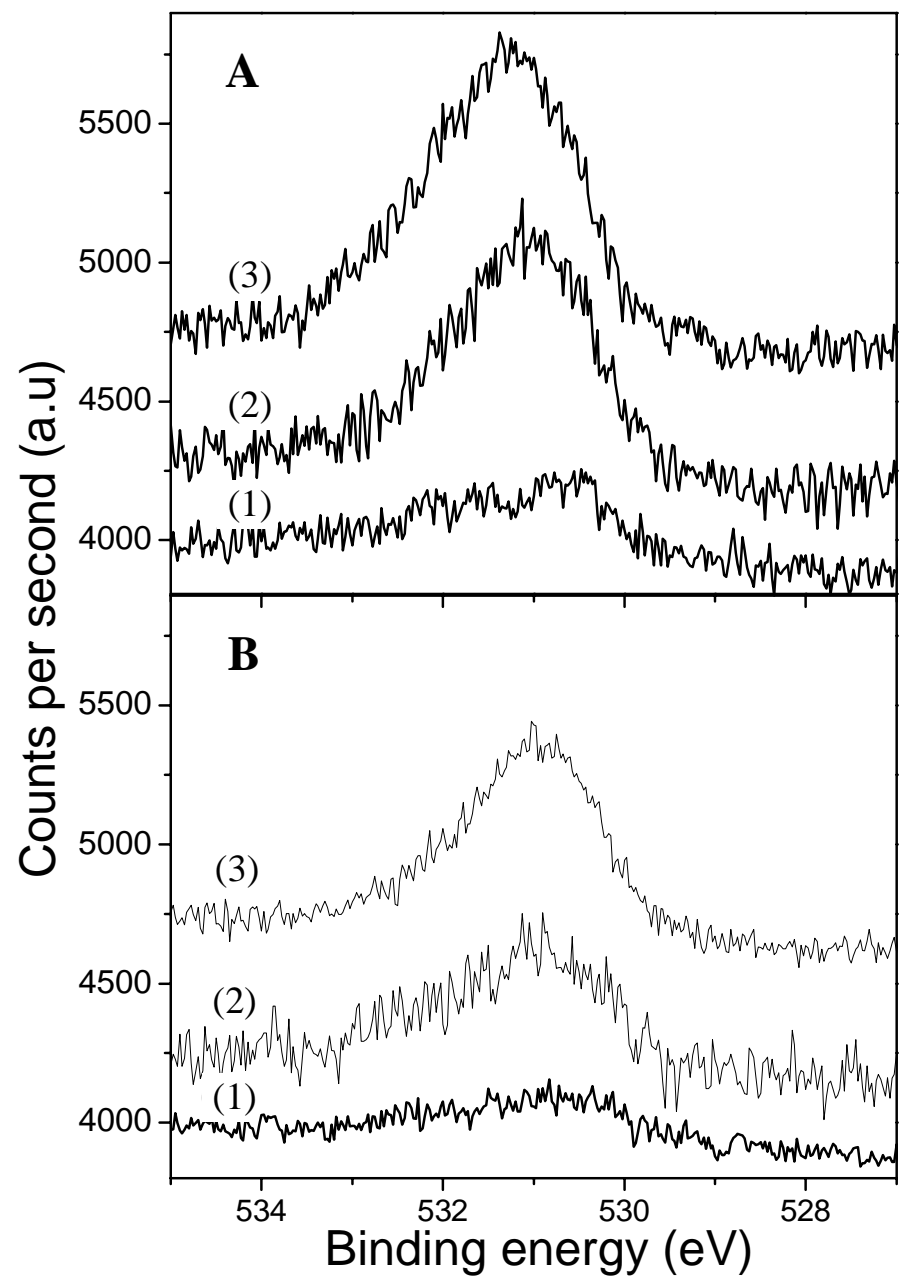

Figure 1: The XPS O 1s peak recorded from: fresh sample (1), after 3 days (2), and after10 days at ambient conditions (3). (A) MT monolayer on GaAs (B) DT monolayer on GaAs . 

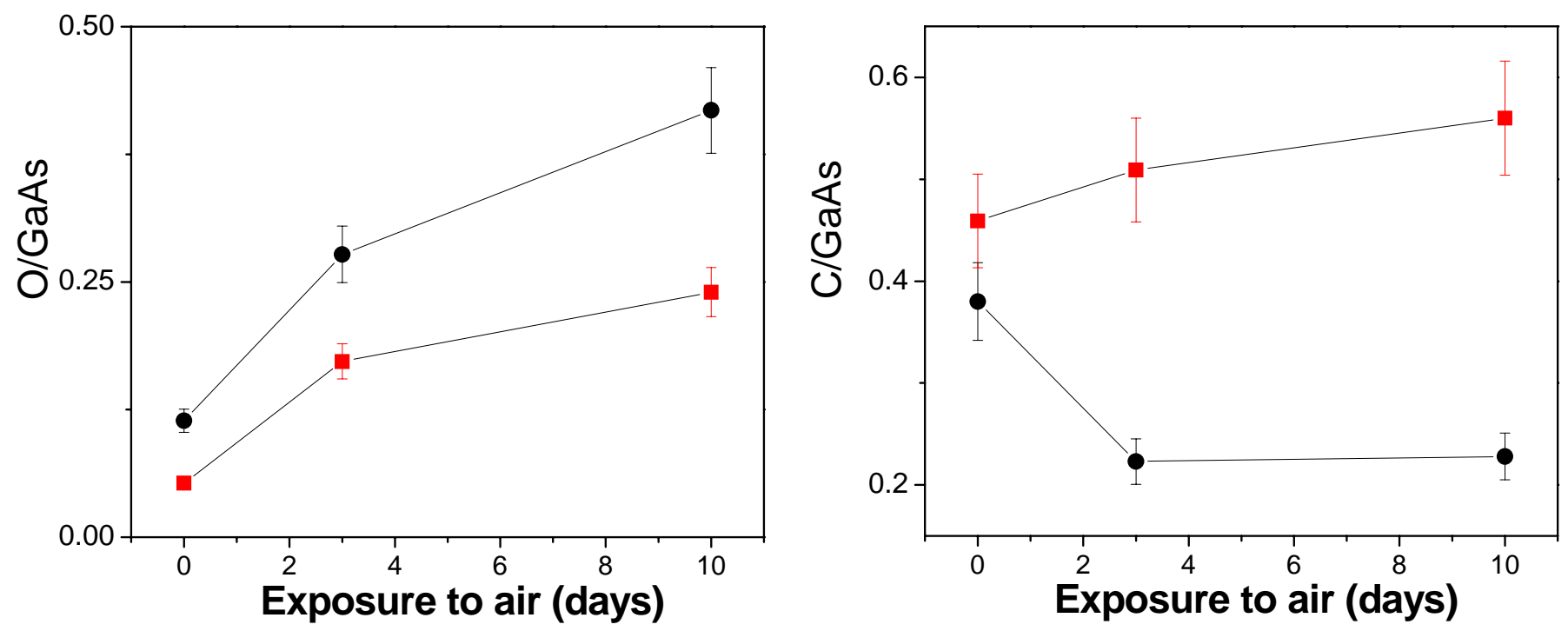

Figure 2: Left: The oxidation level as a function of exposure time to air, represented by the $\mathrm{O} / \mathrm{GaAs}$ ratio. Right: the monolayer stability represented by the $\mathrm{C} / \mathrm{GaAs}$ ratio. The MT data points are black circles and the DT ones are red squares. 